\title{
A Novel Carbazole Derivative, BMVC: a Potential Antitumor Agent and Fluorescence Marker of Cancer Cells
}

\author{
by Cheng-Chung Chang ${ }^{\mathrm{a}}$ ), I-Chun Kuo ${ }^{\mathrm{a}}$ ), Jing-Jer Lin ${ }^{\mathrm{b}}$ ), Yu-Cheng Lu$^{\mathrm{b}}$ ), Chin-Tin Chen ${ }^{\mathrm{c}}$, , \\ Hong-Tsun Back ${ }^{\mathrm{c}}$ ), Pei-Jen Lou ${ }^{\mathrm{d}}$ ), and Ta-Chau Chang*a) \\ a) Institute of Atomic and Molecular Sciences, Academia Sinica, P. O. Box 23-166, Taipei, 106, Taiwan, \\ Republic of China \\ (phone: +886 2-23668231; fax: +886 2-23620200; e-mail: tcchang@po.iams.sinica.edu.tw) \\ b) Institute of Biopharmaceutical Science, National Yang-Ming University, Taipei, 11221, Taiwan, \\ Republic of China \\ c) Center for Optoelectronic Biomedicine, College of Medicine, National Taiwan University, Taipei, Taiwan, \\ Republic of China \\ d) Department of Otolaryngology, National Taiwan University Hospital, Taipei, Taiwan, Republic of China
}

\begin{abstract}
We have investigated a novel compound, 3,6-bis[2-(1-methylpyridinium)vinyl]carbazole diiodide (BMVC), for inhibiting telomerase activity and distinguishing human lung H1299 and oral Ca9-22 cancer cells from lung IMR90 and skin Detroit-551 normal fibroblast cells. The telomeric repeat amplification protocol (TRAP) assay shows that the concentration of BMVC that inhibits $50 \%$ of the telomerase activity $\left(I C_{50}\right)$ is $c a$. $0.05 \mu \mathrm{M}$. On the other hand, the cell-viability assay indicates that the cytotoxicity was less than $15 \%$ to the H1299 and Ca9-22 cancer cells, and almost negligible to the MRC-5 and Detroit-551 normal cells after incubation with $0.5 \mu \mathrm{M}$ BMVC for $72 \mathrm{~h}$. The low concentration of $0.05 \mu \mathrm{M}$ of BMVC can inhibit telomerase activity but does not have general toxic effects to normal cells, implying that BMVC is a promising telomerase inhibitor. Moreover, wide-field fluorescence images of $0.1 \mu \mathrm{M}$ BMVC-treated cells show bright fluorescence spots in the nuclei of the most H1299 and Ca9-22 cancer cells. Interestingly, similar fluorescence spots are hardly observed in the nuclei of the IMR90 and Detroit-551 normal cells, implying that BMVC might be a useful marker to distinguish tumor cells and normal cells.
\end{abstract}

Introduction. - During somatic-cell division, telomeres are progressively shortened as a result of the incomplete lagging-strand replication. A reduction in the telomere length to a critical level can lead to an irreversible growth arrest called cellular senescence [1-3]. In contrast, cancer cells acquire telomerase to maintain short telomeres for the unlimited cell growth. Human telomerase consisting of two major components, a RNA template (hTR) and a telomerase reverse transcriptase (hTERT), allows the addition of the $\mathrm{T}_{2} \mathrm{AG}_{3}$ repeats to maintain telomeric length for indefinite cell growth [4][5]. Although hTR appears in both normal and cancer cells [6], hTERT found in the most cancer cells is absent in most somatic cells [7][8]. Therefore, the detection of hTERT provides a useful method for cancer diagnosis [9].

In addition to its role as a molecular marker for cancer diagnosis, telomerase appears to be an attractive target for cancer chemotherapy because inhibition of telomerase activity could result in telomere shortening, growth arrest, and apoptosis of cancer cells [10]. Two direct approaches, either targeting the RNA template [6][11] or inhibiting the catalytic sites of telomerase reverse transcriptase [8][12], have been applied to inhibit telomerase activity. Another indirect strategy by disrupting the 
telomeric structure has also been developed to inhibit telomerase activity. Telomeres generally consist of many tandem repeats of guanine-rich (G-rich) motifs, for example, the repeated subunits of $\mathrm{T}_{2} \mathrm{AG}_{3}$ in the human telomere [13]. Of particular interest is that the G-rich telomeric repeats are capable of forming an intramolecular Gquadruplex structure with four strands connected by G-quartets [14]. Since the folding of telomeric DNA into G-quadruplexes could hinder telomerase extension [15], molecules that stabilize the G-quadruplex have the potential to interfere with telomere replication and can, therefore, serve as anti-tumor agents [16-18]. Several Gquadruplex stabilizers such as triazines, phenanthrolines, and others have been shown to act as potent telomerase inhibitors [19-21].

Recently, we have synthesized a novel carbazole derivative of 3,6-bis[2-(1methylpyridinium)vinyl]carbazole diiodide (BMVC; Scheme) to stabilize the quadruplex structure of $\mathrm{d}\left(\mathrm{T}_{2} \mathrm{AG}_{3}\right)_{4}$ (Hum) [22] and to illustrate its distinct fluorescence properties [23]. We found that the melting temperature of the quadruplex structure of Hum increases by $c a .13^{\circ}$ upon interacting with BMVC [22]. Since ligand stabilization of the G-quadruplex is generally accompanied by telomerase inhibition [19-21], here we investigate the effect of BMVC on telomerase activity. The TRAP assay shows that the telomerase $I C_{50}$ value of $\mathbf{B M V C}$ is $c a .0 .05 \mu \mathrm{M}$. The cell-viability study indicates that BMVC exhibits very low cytotoxicity toward human lung H1299 and oral Ca9-22 cancer cells and almost negligible effect toward lung MRC-5 and skin Detroit-551 fibroblast cells, even after incubation with $0.5 \mu \mathrm{M} \mathrm{BMVC}$ for $72 \mathrm{~h}$. It appears that BMVC is an attractive telomerase inhibitor. In addition, the fluorescence of BMVC increases significantly by almost two orders of magnitude upon interacting with DNA [23]. Fluorescence microscopy shows that BMVC could enter the human cells, as

Scheme. Synthesis and Structure of BMVC<smiles>Brc1ccc2[nH]c3ccc(Br)cc3c2c1</smiles>

1

b) a)<smiles>C(=C/c1ccc2[nH]c3ccc(/C=C/c4ccncc4)cc3c2c1)\c1ccncc1</smiles>

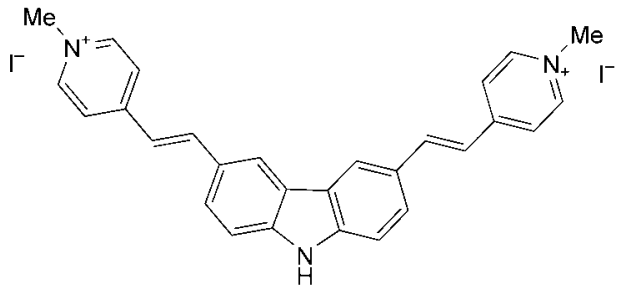

BMVC

a) $\mathrm{Pd}(\mathrm{OAc})_{2},(o \text {-tol })_{3} \mathrm{P}, 4$-vinylpyridine, $\mathrm{Et}_{3} \mathrm{~N}, \mathrm{MeCN}, 105^{\circ}, 3$ d. $\left.b\right) \mathrm{MeI}$, Acetone. 
several bright fluorescence spots were observed in the nucleus. Moreover, the preferential uptake of BMVC by cancer cells suggests that BMVC could be a useful fluorescence marker to distinguish tumor cells from normal cells.

Results. - Telomerase Inhibition. Here, we adopt a modified telomerase assay, TRAP-G4, to evaluate the effects of BMVC on the G-quadruplex for inhibiting telomerase activity [24]. In the TRAP-G4 assay, a G-quadruplex sequence was introduced into the telomerase extension primer that is susceptible to form an intramolecular G-quadruplex. Since the formation of G-quadruplex blocks telomerase extension, this TRAP-T4 assay is capable of evaluating the effects of G-quadruplex stabilizer on telomerase activity. Fig. 1 shows the concentration-dependent effect of carbazole and BMVC on the ladder produced by telomerase extension of a primer. The telomerase $I C_{50}$ values were determined to be $c a$. $0.05 \mu \mathrm{M}$ for BMVC, but larger than $10 \mu \mathrm{M}$ for carbazole. At $0.1 \mu \mathrm{M} \mathbf{B M V C}$, the inhibition of telomerase activity is almost complete while its effects toward Taq DNA polymerase is minimal. Thus, BMVC appears to be a good telomerase inhibitor.

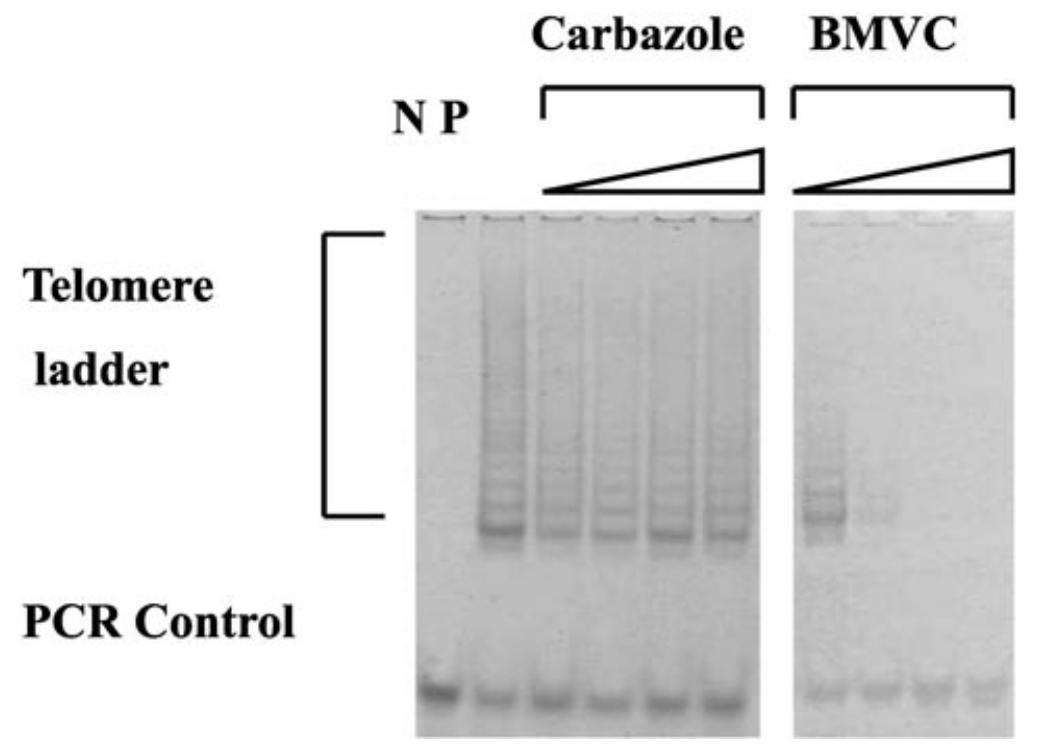

Fig. 1. TRAP-G4 Assay of BMVC and carbazole on telomerase activity. $2 \mu \mathrm{g}$ each of $\mathrm{H} 1299$ cell extracts was mixed with $(\mathrm{N})$ or without RNase $\mathrm{A}(\mathrm{P})$, or with varying concentrations at $0.01,0.1,1$, and $10 \mu \mathrm{M}$ of drugs, and then analyzed for telomerase activity by means of TRAP-G4 assay. Reaction products were separated by $10 \%$ polyacrylamide gel and visualized by CYBER Green I staining of the gel. Positions of telomere ladder are indicated.

Short-Term Cytotoxicity. Cell-viability assays were conducted to examine the cytotoxic effects of BMVC to two human cancer cell lines of lung H1299 and oral Ca922 cells, and two normal fibroblast cell lines of lung MRC-5 and skin Detroit-551 cells. Fig. 2 shows the survival rates of these cells after incubation with $0.5,1,2$, and $4 \mu \mathrm{M}$ BMVC for $72 \mathrm{~h}$. We found that the short-term cytotoxicity to the normal cells was $c a$. $5 \%$ and to the cancer cells $c a$. $40 \%$ after incubation with $4 \mu \mathrm{M}$ BMVC. At a 


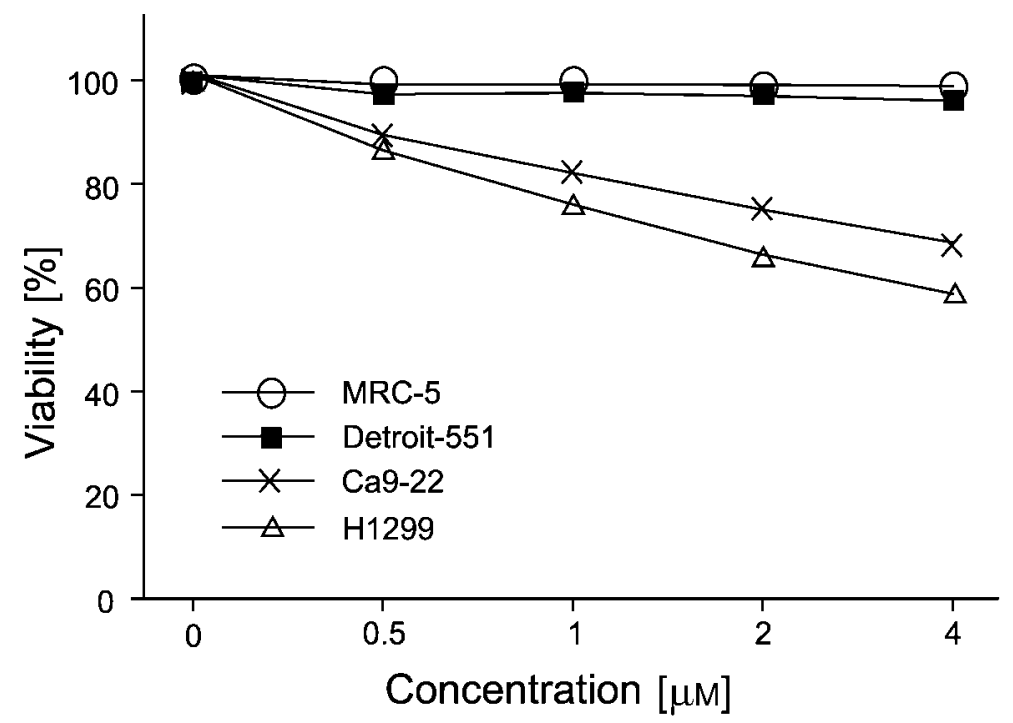

Fig. 2. Cell viability assay of the cell lines of human lung $H 1299$ and oral Ca9-22 cancer cells, and fibroblast lung MRC-5 and skin Detroit-551 normal cells after incubation with 0.5, 1, 2, and $4 \mu \mathrm{M}$ BMVC for $72 \mathrm{~h}$

concentration of $0.5 \mu \mathrm{M} \mathrm{BMVC}$, the cytotoxicity to the cancer cells was less than $15 \%$ and almost negligible to the normal cells.

Intracellular Localization. We further applied wide-field fluorescence microscopy as a tool to determine whether BMVC can enter cells and its intracellular localization. Fig. 3, a, shows a wide-field fluorescence image of $\mathrm{H} 1299$ cells incubated with $0.1 \mu \mathrm{M}$ BMVC for $c a .4 \mathrm{~h}$. Of particular interest is that up to $85 \%$ of $\mathrm{H} 1299$ cells have several bright fluorescence spots in the nuclei after incubation with $0.1 \mu \mathrm{M} \mathrm{BMVC}$ for $3-5 \mathrm{~h}$. Similar fluorescence spots were also observed in the nuclei of $c a .81 \%$ of $\mathrm{Ca} 9-22$ cancer cells. Intriguingly, the bright fluorescence spot is hardly found in the nuclei of Detroit551 and IMR-90 cells under the same experimental conditions. Fig. 3, b shows a typical fluorescence image of Detroit-551 cells after incubation with $0.1 \mu \mathrm{M}$ BMVC for $c a .4 \mathrm{~h}$. In general, the fluorescence of BMVC diffusely distributed throughout the cytoplasm was weak, and most of the nuclear area remains dark. The presence of fluorescent spots in the nuclei of Detroit-551 and IMR-90 cells dropped to $c a$. 17 and $c a$. 5\%, respectively, significantly less than that in cancer cells. To verify if this observation could be applied to other cell types, several human cancer and non-cancer cell lines, including cervical cancer HeLa, lung cancer CL1, nasopharyngeal cancer KJ-1, keratinocyte $\mathrm{HaCaT}$, and lung fibroblast $\mathrm{BJ}-1$, were tested, and the results were in accordance with our current findings (data not shown).

Discussion. -Telomerase Inhibitor. A number of tricyclic aromatic molecules such as acridine derivatives [25], fluorenone derivatives [26], and anthraquinone derivatives [27] have been examined for their potential application in inhibiting telomerase activity. Among them, the trisubstituted acridine derivatives were the most potent, with 
a)

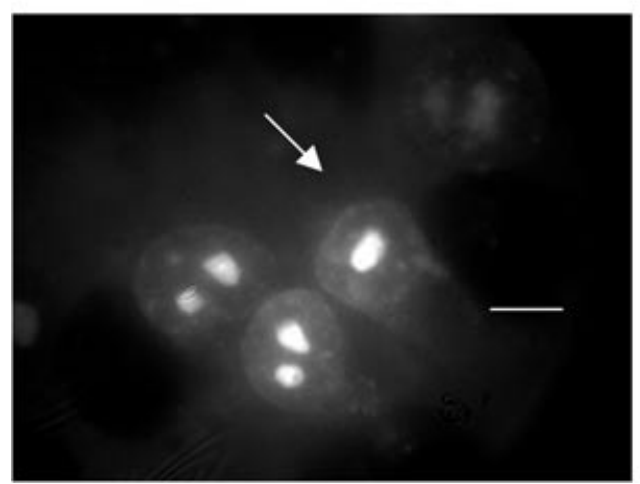

b)

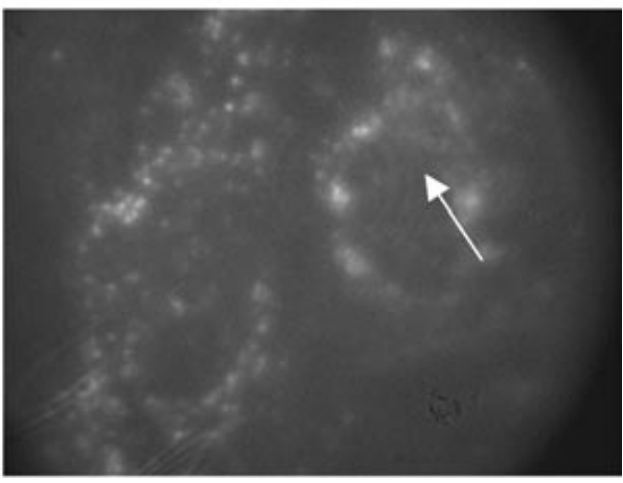

Fig. 3. Wide-field fluorescence images of $H 1299$ cancer cells (a) and Detroit-551 skin fibroblasts $(b)$ after incubation with $0.1 \mu \mathrm{M}$ of BMVC for ca. $4 \mathrm{~h}$. Arrows indicate the nuclei of the cells. The length of the solid reference line is $10 \mu \mathrm{M}$.

telomerase $I C_{50}$ of $0.06-0.1 \mu \mathrm{M}$ [28]. Moreover, it has been shown that, in several systems, there is a good correlation between stabilization of G-quadruplex structure and inhibition of telomerase activity. For instance, the $\Delta T_{\mathrm{m}}$ increases up to $+20^{\circ}$ with the $I C_{50}$ value down to $0.041 \mu \mathrm{M}$ for triazine derivatives [19], the $\Delta T_{\mathrm{m}}$ up to $+19.6^{\circ}$ with the $I C_{50}$ value down to $0.028 \mu \mathrm{M}$ for dibenzophenanthroline derivatives [20], and the $\Delta T_{\mathrm{m}}$ up to $+10.7^{\circ}$ with the $I C_{50}$ value down to $0.018 \mu \mathrm{M}$ for ethidium derivatives [21]. For BMVC, the increase of $\Delta T_{\mathrm{m}}$ by $13^{\circ}$ and an $I C_{50}$ value of $c a .0 .05 \mu \mathrm{M}$ is comparable to the data of these documented molecules.

Because telomerase activity was detected in most of the tumor cells but not in normal somatic cells, a good telomerase inhibitor should selectively affect only tumor cells and not somatic cells. The hypothesis that telomerase inhibition occurs via a quadruplex stabilizer would fulfill two important criteria, namely, potent telomerase inhibition coupled with low cytotoxicity and preferential binding to a specific telomeric DNA structure [28]. It appears that a large therapeutic window between its activity against telomerase and the onset of cytotoxic effects is crucial to apply a telomerase inhibitor as an anti-tumor agent. Here, the cytotoxicity of BMVC is $c a .15 \%$ to the two cancer cells and almost negligible to the two normal cells after incubation with $0.5 \mu \mathrm{M}$ BMVC for $72 \mathrm{~h}$. With respect to the telomerase $I C_{50}$ value of $c a .0 .05 \mu \mathrm{M}$ of BMVC, it appears that BMVC can inhibit telomerase activity but does not have general toxic effects on cells when a low concentration such as $0.05 \mu \mathrm{M}$ was used. Thus, we consider BMVC a promising telomerase inhibitor.

Conventional antitumor agents that bind to duplex DNA typically produce their cytotoxic effect by interfering with transcription or with the function of DNA topoisomerases or related enzymes involved in DNA replication [28]. Therefore, selectivity for quadruplex over duplex DNA is crucial to avoid general cytotoxicity. In our previous work, we showed that the binding preference of BMVC to the quadruplex structure of $\mathrm{d}\left(\mathrm{T}_{2} \mathrm{AG}_{3}\right)_{4}$ is over to the duplex DNA. The fluorescence of $0.2 \mu \mathrm{M}$ BMVC in the PAGE competition assay can clearly reveal the quadruplex structure of 
$\mathrm{d}\left(\mathrm{T}_{2} \mathrm{AG}_{3}\right)_{4}$, but not the duplex DNA [23]. Since the $I C_{50}$ value of BMVC toward telomerase is $0.05 \mu \mathrm{M}, \mathbf{B M V C}$ at such a low concentration preferentially bound to the quadruplex structure of $\mathrm{d}\left(\mathrm{T}_{2} \mathrm{AG}_{3}\right)_{4}$ has a high potential to be used as a potent telomerase inhibitor.

Fluorescence Marker. An active telomerase inhibitor could involve either targeting the RNA template, inhibiting the catalytic sites of telomerase reverse transcriptase, or stabilizing the quadruplex structure of telomeres. Regardless of the mechanism of action, a functional telomerase inhibitor must be capable to enter the nucleus. Here, fluorescence microscopy was applied to examine the cellular localization of BMVC. From fluorescence images of cell lines incubated with $0.1 \mu \mathrm{M}$ BMVC for $3-5 \mathrm{~h}$, the bright fluorescence spots were observed in the nuclei of the H1299 and Ca9-22 cancer cells. In contrast, much less accumulation of BMVC in the nucleus was detected in the Detroit-551 and IMR-90 normal cells. These results suggested that BMVC could be used as a fluorescence marker to distinguish cancer cells from normal cells. In addition, the localization of the fluorescence spots indicated that the BMVC taken up into the cells would enter the nucleus.

Furthermore, the preferential uptake of BMVC into the nuclei of cancer cells could partially explain the observed higher short-term cytotoxic effects to the cancer cells. At present, the correlation between the cellular uptake into the nucleus and cell cytotoxicity of BMVC is unclear. Nevertheless, better understanding of the mechanism of the cellular uptake into the nucleus might provide additional selection for the development of anti-tumor agents.

Conclusions. - In summary, we have demonstrated that BMVC is an attractive molecule for the potential to be developed as an anti-tumor agent. BMVC has a low telomerase $I C_{50}$ value of $c a .0 .05 \mu \mathrm{M}$ with almost no cytotoxic effect at this concentration. The binding preference of BMVC to the quadruplex is over to the duplex DNA. BMVC is soluble in water and could enter the nuclei after the uptake by cancer cells. On the basis of these results, we consider that BMVC is a potential antitumor agent. On the other hand, distinct fluorescence characters of BMVC suggested that it might be useful to distinguish cancer cells from normal cells. Investigation of the differences in fluorescence spots between cancer cells and normal cells may provide new insights into cellular uptake into the nucleus and telomerase inhibition. It is conceivable that the interaction of BMVC with normal cells and tumor cells warrants extensive investigation.

This work was supported by Academia Sinica and the National Science Council of the Republic of China (Grants NSC 91-2113-M001-028, NSC-91-3112-B010-008, NSC-91-2320-B002-097-M08, NSC91-2314-B002-100).

\section{Experimental Part}

Chemistry. 9H-Carbazole and 3,6-dibromo-9H-carbazole were purchased from Aldrich and used without further purification. Synthesis of BMVC molecule is shown in the Scheme, and the details have been described elsewhere [22]. Briefly, compound 2 was synthesized from 3,6-dibromo- $9 H$-carbazole through Heck reaction in good yield, and it is only sparingly soluble in $\mathrm{H}_{2} \mathrm{O}$. BMVC was collected after refluxing 2 with excess $\mathrm{MeI}$ in acetone. BMVC was obtained in very good yield, and it is soluble in $\mathrm{H}_{2} \mathrm{O}$.

Telomerase-Activity Assay. A modified telomeric-repeat-amplification protocol (TRAP-G4) was utilized for G-quadruplex-induced telomerase activity assay [24]. Telomerase-extended products were resolved by $10 \%$ 
polyacrylamide gel electrophoresis and visualized by CYBER Green I staining of the gels. As a source for telomerase, total cell lysates derived from lung cancer cell line H1299 cells were used. Protein concentration of the lysates was determined by means of a Bio-Rad assay kit and with BSA as standards.

Cell-Viability Assay. Stock cell cultures were grown in 96-well plates (ca. 5000 cells/well) in Dulbecco's modified Eagle's medium (DMEM) containing $10 \%$ fetal calf serum in a $5 \% \mathrm{CO}_{2}$ incubator at $37^{\circ}$. For examining the short-term cytotoxic effect, cells were then incubated with different concentrations of BMVC at $0.5,1,2$, and $4 \mu \mathrm{M}$ for $72 \mathrm{~h}$. The cytotoxicity of BMVC to cells was determined with MTT (3-(4,5dimethylthiazol-2-yl)-2,5-diphenyltetrazolium bromide) as a substrate. The MTT assay is based on the activity of mitochondria dehydrogenases, which can reduce a $\mathrm{H}_{2} \mathrm{O}$-soluble tetrazolium salt to a purple insoluble formazan product. The amount of MTT formazan product was analyzed spectrophotometrically at the absorbance of $556 \mathrm{~nm}$. Non-treated cells were used as control. Each individual cytotoxic experiment was repeated for three times.

Wide-Field Fluorescence Microscopy. Cells were incubated with $0.1 \mu \mathrm{M}$ BMVC in normal culture medium for $c a .4 \mathrm{~h}$. After the incubation, the non-fixed cells were washed three times with PBS and then processed for imaging study. The construction of a wide-field fluorescence microscopy was described in [29]. Fast imaging of wild-field microscopy consists of an $\mathrm{Ar}^{+}$laser (Coherent) as a light source and a sensitive cooled chargedcoupled device (CCD) camera (Andor, DV465-UV) for detecting image. Excitation and imaging was conducted by an oil-immersion microscope objective with a numerical aperature of 1.3 . A dichroism mirror (Omega) directed the fluorescence to a CCD camera. A holographic Notch filter (Oriel) blocked the backscattered laser light. The images of $250 \times 250$ pixels were recorded at high speed. The imaged area was $50 \times 50 \mu \mathrm{m}^{2}$ and the spatial resolution was $c a .2$ pixels.

\section{REFERENCES}

[1] C. B. Harley, A. B. Futcher, C. W. Greider, Nature 1990, 345, 458.

[2] V. Lundblad, J. W. Szostak, Cell 1989, 57, 633.

[3] L. L. Sandell, V. A. Zakian, Cell 1993, 75, 729.

[4] C. W. Greider, E. H. Blackburn, Cell 1987, 51, 887.

[5] J. W. Shay, S. Bacchetti, Eur. J. Cancer 1997, 5, 787.

[6] J. Feng, W. D. Funk, S. S. Wang, S. L. Weinrich, A. A. Avilon, C. P. Chu, R. R. Adams, E. Chang, R. C. Allsop, J. Y. Siyuhan Le, M. D. West, C. B. Harley, W. H. Andrews, C. W. Greider, B. Villeponteau, Science 1995, 269, 1236.

[7] N. W. Kim, M. A. Piatyszek, K. R. Prowas, C. B. Harley, M. D. West, P. L. Ho, G. M. Coviello, W. E. Wright, S. L. Weinrich, J. W. Shay, Science 1994, 266, 2011.

[8] T. M. Nakamura, G. B. Morin, K. B. Chapman, S. L. Weinrich, W. H. Andrews, J. Linger, C. B. Harley, T. R. Cech, Science 1997, 277, 955.

[9] R. A. Breslow, J. W. Shay, A. F. Gazdar, S. Srivastava, J. Natl. Cancer Inst. 1997, 89, 618.

[10] E. H. Blackburn, Nature 1991, 350, 569.

[11] S. Kondo, Y. Kondo, G. Li, R. H. Silverman, J. K. Cowell, Oncogene 1998, 16, 3323.

[12] W. C. Hahn, S. A. Stewart, M. W. Brooks, S. G. York, E. Eaton, A. Kurachi, R. L. Beijersbergen, J. H. Knoll, M. Meyerson, R. A. Weinberg, Nat. Med. 1999, 5, 1164.

[13] G. B. Morin, Cell 1989, 59, 521.

[14] M. Gellert, M. N. Lipsett, D. R. Davies, Proc. Natl. Acad. Sci. U.S.A. 1962, 48, 2013.

[15] A. M. Zahler, J. R. Williamson, T. R. Cech, D. M. Prescott, Nature 1991, 350, 718.

[16] J. L. Mergny, C. Hélène, Nat. Med. 1998, 4, 1366.

[17] H. Han, L. H. Hurley, Trends Pharmacol. Sci. 2001, 21, 136.

[18] S. M. Kerwin, Curr. Pharm. Des. 2000, 6, 441.

[19] J. L. Mergny, L. Lacroix, M.-P. Teulade-Fichou, C. Hounsou, L. Guittat, M. Hoarau, P. B. Arimondo, J.-P. Vigneron, J.-M. Lehn, J.-F. Riou, T. Garestier, C. Hélène, Proc. Natl. Acad. Sci. U.S.A. 2001, $98,3062$.

[20] J. F. Riou, L. Guittat, P. Mailliet, A. Laoui, E. Renou, O. Petitgenet, F. Mégnin-Chanet, C. Hélène, J.-L. Mergny, Proc. Natl. Acad. Sci. U.S.A. 2002, 99, 2672.

[21] F. Koeppel, J.-F. Riou, A. Laoui, P. Mailliet, P. B. Arimondo, D. Labit, O. Petitgenet, C. Hélène, J.-L. Mergny, Nucleic Acids Res. 2001, 29, 1087.

[22] C.-C. Chang, J.-Y. Wu, T.-C. Chang, J. Chin. Chem. Soc. 2003, 50, 185. 
[23] C.-C. Chang, J.-Y. Wu, C.-W. Chien, W.-S. Wu, H. Liu, C.-C. Kang, L.-J. Yu, T.-C. Chang, Anal. Chem. 2003, $75,6177$.

[24] D. Gomez, J. L. Mergny, J. F. Riou, Cancer Res. 2002, 62, 3365.

[25] P. J. Perry, A. P. Reszka, A. A. Wood, M. A. Read, S. M. Gowan, H. S. Dosanjh, J. O. Trent, T. C. Jenkins, L. R. Kelland, S. Neidle, J. Med. Chem. 1998, 41, 4873.

[26] P. J. Perry, T. C. Jenkins, Exp. Opin. Invest. Drug. 1999, 8, 1981.

[27] P. J. Perry, M. A. Read, R. T. Davies, S. M. Gowan, A. P. Reszka, A. A. Wood, L. R. Kelland, S. Niedle, J. Med. Chem. 1999, 42, 2679.

[28] M. Read, R. J. Harrison, B. Romabnoli, F. A. Tanious, S. H. Gowan, A. P. Reszka, W. D. Wilson, L. R. Kelland, S. Neidle, Proc. Natl. Acad. Sci. U.S.A. 2001, 98, 4844.

[29] T. Y. Latychevskaia, K. K. Liang, M. Hayashi, C. H. Chang, A. Renn, U. P. Wild, J. H. Hsu, T.-C. Chang, S. H. Lin, J. Chin. Chem. Soc. 2003, 50, 477. 